\author{
Ф.А. Гельвер ${ }^{1,2}$, И.В. Белоусов ${ }^{2,1}$ В.Ф. Самосейко ${ }^{2,1}$ \\ 1Филиал «ЦНИИ СЭТ» ФГУП «Крыловский государственный научный центр», \\ Санкт-Петербург, Россия \\ ${ }^{2}$ ГУМФ им. адмирала С.О. Макарова, Санкт-Петербург, Россия

\section{ГРЕБНЫЕ ЭЛЕКТРИЧЕСКИЕ УСТАНОВКИ СУДОВ БОЛЬшой мощности}

\begin{abstract}
Выполнен анализ существующих структур построения систем электродвижения судов большой мощности, представлены их достоинства и недостатки. Произведен сравнительный анализ различных типов гребных электродвигателей. На основе анализа предложено использовать в качестве гребного электродвигателя реактивный электродвигатель с анизотропной магнитной проводимостью ротора, отличающийся высокими энергетическими и лучшими эксплуатационными характеристиками по сравнению с другими известными типами электрических машин. Произведен сравнительный анализ различных типов электрических преобразователей используемых в регулируемом электроприводе, рассмотрены достоинства и недостатки. Предложена бестрансформаторная структура электродвижительной установки судна большой мощности с каскадным преобразователем частоты. Рассмотрены различные варианты схем построения бестрансформаторных гребных электроприводов с каскадным преобразователем частоты. Приведены достоинства использования систем электродвижения судов с каскадным преобразователем частоты и реактивным электродвигателем с анизотропной магнитной проводимостью ротора. Предложенная структура универсальна, обладает высокой надежностью и гибкостью построения, а также позволяет реализовать электродвижительную установку практически неограниченной мощности. На основе предложенной структуры электродвижительного комплекса судна выполнено проектирование альтернативного варианта построения электродвижительного комплекса ледокола проекта 22220. Представлены сравнительные диаграммы удельных показателей массы и объема, занимаемого электродвижительным комплексом, проекта 22220 изготовленного варианта и альтернативного бестрансформаторного варианта структуры электродвижительной установки с каскадным преобразователем частоты и реактивной электрической машиной с анизотропной магнитной проводимостью ротора. Приведенные количественные оценки показывают, что использование бестрансформаторного варианта структуры электродвижительной установки с каскадным преобразователем частоты и реактивной электрической машиной с анизотропной магнитной проводимостью ротора позволят значительно уменьшить массу и объем, занимаемый электродвижительным комплексом. Кроме того, предложенный вариант электродвижительного комплекса судна позволит значительно улучшить эксплуатационные характеристики по сравнению с известными структурами построения движительного комплекса.

Ключевые слова: реактивная машина с анизотропной магнитной проводимостью ротора (РЭМАМПР), продольная и поперечная шихтовка ротора, массогабаритные характеристики, каскадный электрический преобразователь частоты, ячейка, трехфазно-однофазный преобразователь частоты, синтезируемые уровни напряжения, бестрансформаторная структура.
\end{abstract}




\author{
F.A. Gelver ${ }^{1,2}$, I.V. Belousov ${ }^{2,1}$, V.F. Samoseiko ${ }^{2,1}$ \\ ${ }^{1}$ Branch of the Central Research Institute SET, FSUE Krylov State Research \\ Center, Saint Petersburg, Russian Federation \\ ${ }^{2}$ GUMRF named after Admiral S.O. Makarova, Saint Petersburg, Russian Federation
}

\title{
ELECTRICAL PROPULSION PLANT OF SHIPS, HEAVY-DUTY
}

\begin{abstract}
The analysis of the existing structures of the construction of systems for the electromotive movement of vessels of high power is performed, their advantages and disadvantages are presented. A comparative analysis of various types of propeller motors. Based on the analysis, it was proposed to use a reactive electric motor with anisotropic magnetic conductivity of the rotor, characterized by high energy and better performance characteristics compared to other known types of electric machines, as a propeller motor. A comparative analysis of various types of electrical transducers used in an adjustable electric drive was carried out, advantages and disadvantages were considered. A transformerless structure of an electromotive installation of a large-capacity vessel with a cascade frequency converter is proposed. Various variants of the design of transformerless rowing electric drives with a cascade frequency converter are considered. The advantages of using ship propulsion systems with a cascade frequency converter and a jet motor with anisotropic magnetic conductivity of the rotor are given. The proposed structure is universal, has high reliability and flexibility of construction, and also allows the implementation of an electromotive installation of almost unlimited power. On the basis of the proposed structure of the ship's electromotive complex, an alternative variant for constructing an electromotive complex of an icebreaker of project 22220 was designed. magnetic wire imostyu rotor. The presented quantitative estimates show that the use of a transformerless variant of the structure of an electromotive installation with a cascade frequency converter and a reactive electric machine with anisotropic magnetic conductivity of the rotor will significantly reduce the mass and volume occupied by the electromotive complex. In addition, the proposed version of the electromotive complex of the vessel will significantly improve performance in comparison with the known structures of building a propulsion complex.

Keywords: reactive machine with anisotropic magnetic conductivity of the rotor (RAMAMPR), longitudinal and transverse loading of the rotor, mass and size characteristics, cascade electric frequency converter, cell, three-phase-single-phase frequency converter, synthesized voltage levels, transformerless structure.
\end{abstract}

Введение. В последнее время в отечественном судостроении наметилась тенденция строительства специальных типов судов и кораблей большой мощности с использованием систем электродвижения [1-3]. Использование систем электродвижения позволяет получить лучшие эксплуатационные и энергетические характеристики по сравнению с системами, использующими механическую передачу от теплового двигателя к валу винта $[1,2]$. Особенно данная тенденция постройки характерна для судов и кораблей, у которых гребная электрическая установка является единственным типом установки, удовлетворяющим жестким требованиям эксплуатационного характера.

Вопросам проектирования и эксплуатации систем электродвижения уделяется большое внимание. Их разработкой и совершенствованием заняты все ведущие производители судостроительной области. 
Получение новых эксплуатационных качеств у современных типов судов и кораблей ведет к увеличению мощности гребных электроприводов, что стимулирует внедрение новых технологий в системы электродвижения судов.

Так, модернизация ледокольного флота нашей страны и амбициозные планы по строительству самых мощных в мире ледоколов связаны с планами освоения новых территорий Арктики, а также возможностью круглогодичного использования Северного морского пути [4]. Необходимость повышения мощности таких ледоколов вызвана еще и тем, что они должны иметь широкий корпус для осуществления проводки танкеров класса «афромакс» и прочих судов и кораблей по Северному морскому пути с высокой скоростью. Существующие ледоколы этого делать не могут. Поэтому мощность гребных электродвигателей постоянно повышается. Кроме судов гражданского флота системы полного электродвижения начинают масштабно внедряться на корабли и подводные лодки ВМФ. Суммарная мощность электроустановок таких судов и кораблей доходит до сотен МВт.

На Балтийском заводе сегодня изготавливают три атомных ледокола проекта 22220 с мощностью гребной электрической установки 60 МВт (3 винта по 20 МВТ) [5, 6]. В 2015 г. ОАО «ЦКБ “Айсберг”» совместно с ФГУП «Крыловский государственный научный центр» в рамках реализации федеральной целевой программы «Развитие гражданской морской техники на 2009-2016 гг.» разработали концептуальный проект атомного ледокола «Лидер» с суммарной установленной мощностью на гребных винтах 120 МВт (4 винта по 30 МВт на каждом) $[6,7]$. В военном кораблестроении системы полного электродвижения реализованы на подводных лодках и на нескольких типах судов вспомогательного флота. Так, за последние 10 лет в рамках государственного оборонного заказа в ЦМКБ «Алмаз», в КБ «Вымпел» совместно с филиалом «ЦНИИ СЭТ» ФГУП «Крыловский государственный научный центр» спроектированы и внедрены единые электроэнергетические системы ЭЭС с системами электродвижения для ряда новых судов: проект 19910 - гидрографичекское судно «Вайгач»; проект 20180 транспортно-поисковое судно «Звездочка»; проект 21300 - спасательное судно «Игорь Белоусов»; проект 22030 - морской спасательный буксир «Охотск»; проект 21180 - ледокол «Илья Муромец» и другие [6]. Наибольшая установленная мощность уже сданных в эксплуатацию 
судов доходит до 7 МВт. Эксплуатация таких судов подтвердила высокие эксплуатационные качества систем электродвижения.

В системах электродвижения используется электрическая технология передачи энергии от теплового двигателя к гребному электрическому двигателю, которая предполагает выработку электроэнергии, согласование и преобразование ее параметров для управления гребным электродвигателем (рис. 1).

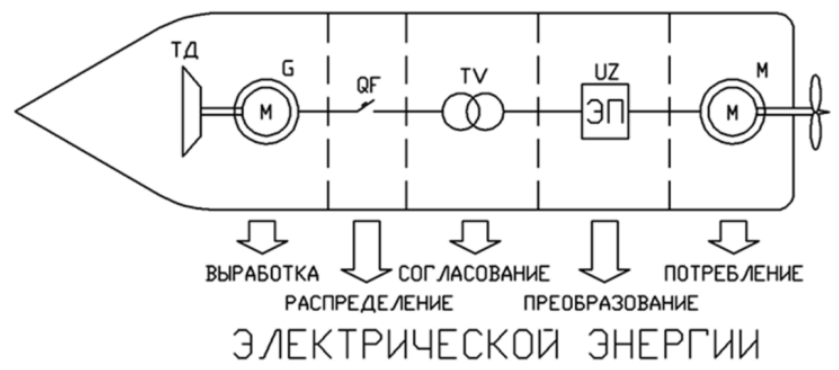

Рис. 1. Структура движительного комплекса судна, наиболее распространенная на данный момент времени

Такая структура движительного комплекса характерна для всех ранее упоминаемых проектов и состоит из первичного теплового двигателя, электрического генератора, распределительного устройства, согласующего трансформатора, преобразователя частоты и гребного электродвигателя [6]. Каждый из элементов данной структуры выполнен на полную мощность движительного комплекса, следовательно, имеет большие габариты и массу. С ростом установленной мощности системы электродвижения возникают существенные проблемы с реализацией, размещением, компоновкой и обеспечением ее надежной работы.

К настоящему времени накоплен опыт использования различных типов гребных электродвигателей. Особенностями гребных электродвигателей являются большая мощность и низкие обороты вращения ротора. Массогабаритные показатели двигателя определяются величиной его электромагнитного момента. Поскольку гребные электродвигатели имеют большую мощность и низкие обороты вращения ротора, то их массогабаритные показатели значительно уступают таковым высокооборотных электродвигателей. При этом согласующий трансформатор в такой структуре по массогабаритным показателям мало уступает гребному электродвигателю. Электрический преобразователь в структуре, изображенной на рис. 1, содержит большое количество 
дорогих и сложных элементов. При большой мощности возникают трудности с его реализацией на существующей элементной базе. Выпускаемая номенклатура силовых электронных ключей на большие токи и напряжения весьма ограничена, а по допустимым значениям тока и напряжения имеется технологический предел, ограничивающий мощность проектируемых электрических преобразователей.

Кроме этих задач еще много разнообразных задач, связанных с алгоритмами управления электропривода движительного комплекса, которые позволят улучшить энергетические и эксплуатационные характеристики. Указанным проблемам посвящено множество публикаций и исследований, что свидетельствует об актуальности выбора структуры движительного комплекса судна $[1,3,8]$.

Таким образом, широкое применение систем электродвижения на различных типах судов ограничено большой массой, габаритами, стоимостью, а также низкой надежностью и сложностью используемого электрооборудования. При практической реализации систем электродвижения встает вопрос их технической реализуемости, связанной с возможностью размещения электрооборудования на ограниченных площадях судна. Еще одним фактором, ограничивающим использование систем электродвижения, является их сложность, требующая высокой квалификации обслуживающего и ремонтного персонала. Рост установленной мощности систем электродвижения требует разработки, проектирования и внедрения как новой современной элементной базы, так и новых схемотехнических решений при построении электродвижительного комплекса судна [1].

В данной работе предлагается при проектировании электродвижительного комплекса судна большой мощности рассматривать гребной электропривод и систему его электроснабжения как единое целое. Такой комплексный подход к системе электродвижения судна позволит улучшить ее массогабаритные, энергетические и эксплуатационные характеристики.

Выбор типа электромеханического преобразователя. В качестве гребных электродвигателей находят применение все типы классических электрических машин (синхронные (СД), асинхронные (АД), постоянного тока (ДПТ)), у которых обмотки находятся как на статоре, так и на роторе. 
Альтернативой структуре электродвижения, изображенной на рис.1, является система Г-Д (генератор-двигатель) [9], которая является лучшей по критерию массогабаритных показателей. Однако она имеет ограничения по мощности и ряд недостатков эксплуатационного характера, связанных с использованием ДПТ. На вновь строящихся судах ДПТ в качестве гребных электродвигателей не используются.

Самым распространенным типом гребного электродвигателя был и остается асинхронный электродвигатель с короткозамкнутым ротором. Однако в настоящее время внимание специалистов, занимающихся гребным электроприводом, обращено на электрические машины различных конструкций, у которых обмотки на роторе отсутствуют. Это синхронные машины с постоянными магнитами (СМПМ) и реактивные машины, имеющие пассивный ротор [10, 11]. Отсутствие потерь мощности в роторе у крупных машин упрощает систему их охлаждения и является их большим достоинством [12].

$\mathrm{У}$ реактивных машин намагничивание ротора происходит за счет токов в обмотке статора. Для фиксации и размещения магнитных полюсов на роторе реактивной машины используются различные конструктивные решения. Одним из вариантов конструкции ротора реактивной машины является его зубчатая форма [10]. Другой вариант конструкции ротора применяется у реактивных машин с анизотропной магнитной проводимостью ротора (РЭМАМПР) [11]. Существуют два вида конструктивных решений, позволяющих придать материалу ротора анизотропные магнитные свойства: продольная шихтовка ротора изогнутыми определенным образом стальными листами (РЭМАМПР-А) $[13,14]$; поперечная шихтовка ротора стальными листами со специальными вырезами (РЭМАМПР-Т) [15, 16].

Для намагничивания магнитопровода электрических машин получили распространение два типа обмоток на статоре. Одна обмотка классического типа, как правило, распределенная, она состоит из нескольких фазных обмоток, имеющих между собой магнитные связи [11]. Обмотка другого типа также состоит из нескольких фазных обмоток, образованных двумя секциями с короткими лобовыми частями. Короткие лобовые части обусловливают отсутствие магнитных связей между фазами. Статор таких обмоток имеет зубчатую форму [10]. Машины с зубчатым статором и ротором называют также вентильно-индукторными (ВИ). 
Считается, что РЭМАМПР-Т более технологична в изготовлении, и такую четырехполюсную машину промышленно выпускает фирма АВВ. Гребные электрические двигатели имеют низкую частоту вращения ротора, следовательно, как правило, их выполняют многополюсными. Конструктивно РЭМАМПР-Т весьма проблематично изготовить с большим числом пар полюсов, а вот РЭМАМПР-А можно выполнить практически с любым требуемым числом пар полюсов. Кроме того, по энергетической эффективности РЭМАМПР-А лучше, чем РЭМАМПР-Т [17]. Поэтому при изготовлении гребных электродвигателей предпочтение может быть отдано РЭМАМПР-А [12].

В 2015 г. совместно с ПАО «НИПТИЭМ» была спроектирована и изготовлена шестиполюсная РЭМАМПР-Т мощностью 500 кВТ на номинальную частоту вращения 1000 об/мин, которая прошла успешные испытания и подтвердила высокие энергетические и эксплуатационные характеристики. На данный момент времени в филиале «ЦНИИ СЭТ» ФГУП «Крыловский государственный научный центр» спроектирована и изготавливается двадцатиполюсная РЭМАМПР-А мощностью 1,7 МВт на номинальную частоту вращения 300 об/мин.

В таблице приведены достоинства и недостатки рассмотренных типов электрических машин. Согласно таблице большинством достоинств, а также лучшими эксплуатационными характеристиками обладает реактивная электрическая машина с анизотропной магнитной проводимостью ротора (РЭМАМПР).

Достоинства и недостатки наиболее распространенных типов электрических машин переменного тока

\begin{tabular}{|c|c|c|}
\hline Двигатель & Достоинства & Недостатки \\
\hline АД & $\begin{array}{l}\text { - Возможность работы во второй зоне; } \\
\text { - Отработанная технология изготовления; } \\
\text { - Возможность управлять намагниченно- } \\
\text { стью магнитопровода }\end{array}$ & $\begin{array}{l}\text { - Наличие больших потерь мощности } \\
\text { в роторе и необходимость отвода тепла от } \\
\text { ротора; } \\
\text { - Низкий коэффициент полезного действия }\end{array}$ \\
\hline СД & $\begin{array}{l}\text { - Возможность работы во второй зоне; } \\
\text { - Хорошие энергетические характеристики; } \\
\text { - Возможность управлять намагниченно- } \\
\text { стью магнитопровода }\end{array}$ & $\begin{array}{l}\text { - Необходимость электрического преобразова- } \\
\text { теля для управления обмоткой возбуждения } \\
\text { и обмоткой возбуждения и статора; } \\
\text { - Наличие подвижного электрического } \\
\text { контакта; } \\
\text { - Потери в роторе }\end{array}$ \\
\hline СДМП & $\begin{array}{l}\text { - Лучшие энергетические характеристики; } \\
\text { - Отсутствие электрических потерь } \\
\text { в роторе }\end{array}$ & $\begin{array}{l}\text { - Невозможность снять возбуждение, что при } \\
\text { возникновении аварийных режимов может } \\
\text { приводить к катастофическим последствиям; } \\
\text { - Дороговизна магнитов; } \\
\text { - Сложная технология изготовления ротора; } \\
\text { - Низкий уровень ремонтопригодности } \\
\text { на объекте }\end{array}$ \\
\hline
\end{tabular}


Окончание таблицы

\begin{tabular}{|c|c|c|}
\hline Двигатель & Достоинства & Недостатки \\
\hline ВИ & $\begin{array}{l}\text { - Простота изготовления; } \\
\text { - Простой коммутатор; } \\
\text { - Отсутствие электрических потерь в роторе }\end{array}$ & $\begin{array}{l}\text { - Большая масса; } \\
\text { - Большое количество коммутаторов } \\
\text { и кабелей }\end{array}$ \\
\hline РЭМАМПР & $\begin{array}{l}\text { - Простая конструкция } \\
\text { - Хорошие энергетические характеристики; } \\
\text { - Возможность работы во второй зоне; } \\
\text { - Лучшие массогабаритные характеристики; } \\
\text { - Отсутствие электрических потерь } \\
\text { в роторе; } \\
\text { - Возможность управлять намагниченно- } \\
\text { стью магнитопровода }\end{array}$ & $\begin{array}{l}\text { - Неотработанная технология проектиро- } \\
\text { вания роторов крупных электрических } \\
\text { машин }\end{array}$ \\
\hline
\end{tabular}

Сравнить массогабаритные характеристики различных типов электрических машин, приведенных в таблице, можно с использованием данных гребных электрических машин, имеющихся в существующих проектах ледоколов и буксиров. На рис. 2 и 3 приведены диаграммы удельной массы и удельного объема гребных электродвигателей. Из данных диаграмм следует, что лучшими массогабаритными показателями обладает РЭМАМПР.

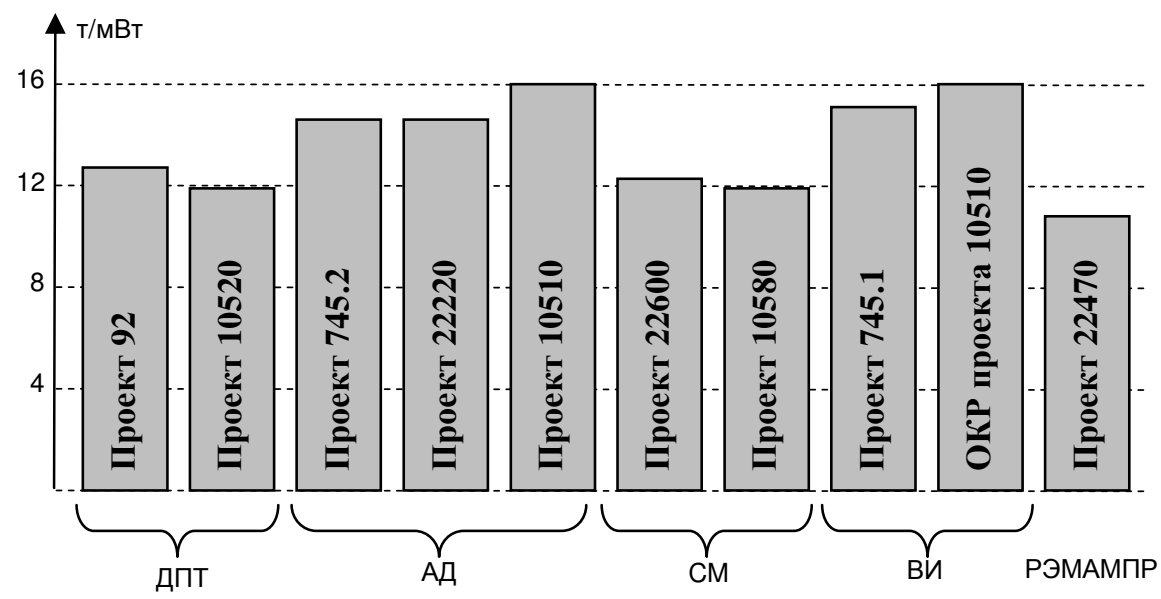

Рис. 2. Диаграмма удельной массы гребных электродвигателей на ледоколах и буксирах различных проектов

Из приведенного анализа следует, что электропривод с РЭМАМПР по энергетическим характеристикам превосходит самый распространенный электропривод с АД. Кроме того, по ряду эксплуатационных характеристик, надежности и безопасности, а также технологии изготовления, особенно для электрических машин большой мощности, РЭМАПР превосходит все известные типы электрических машин. 


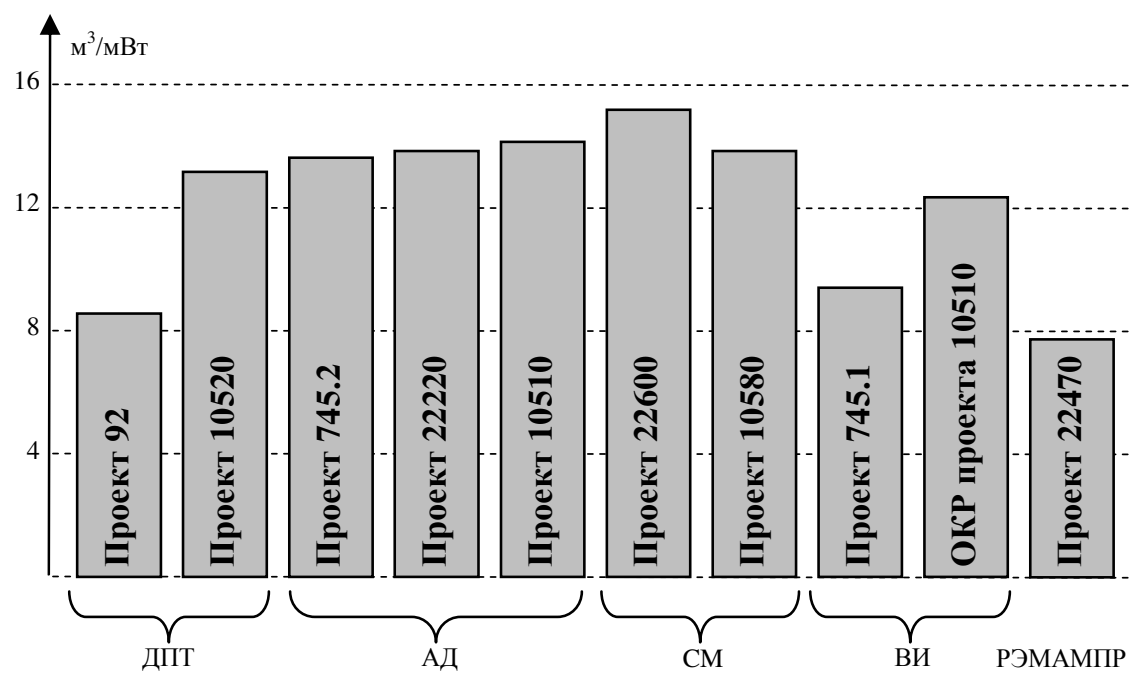

Рис. 3. Диаграмма удельного объема гребных электродвигателей на ледоколах и буксирах различных проектов

Выбор типа электрического преобразователя. Для управления гребными электродвигателями используются электрические преобразователи, построенные с использованием силовых электронных ключей. Предельные мощности электрических преобразователей ограничивает коммутационная способность электронных ключей, выпускаемых на данный момент времени. В качестве электрического преобразователя наибольшее распространение получили непосредственные преобразователи частоты и преобразователи частоты со звеном постоянного тока, построенные с использованием силовых электронных ключей. Непосредственные преобразователи частоты реализуются в основном на полууправляемых полупроводниковых ключах-тиристорах, а преобразователи частоты со звеном постоянного тока - на полностью управляемых полупроводниковых ключах-транзисторах. Отличительной особенностью непосредственных преобразователей частоты является однократное преобразование электрической энергии и простота построения силовой части электрического преобразователя. К недостаткам непосредственных преобразователей частоты относятся: низкое качество синтезируемого напряжения, а также значительные ограничения по диапазону регулирования скорости. Кроме того, к недостаткам следует отнести возможность ложного срабатывания и самопроизвольного открытия тиристоров. Тем не менее следует отметить, что непосредственные 
преобразователи частоты имеют неоспоримые преимущества по массогабаритным характеристикам и имеют право на использование.

В последнее время во всех отраслях промышленности практически все регулируемые электроприводы строят на основе преобразователей частоты со звеном постоянного тока, которые состоят из выпрямителя и инвертора. В гребных электроприводах для увеличения единичной установленной мощности таких преобразователей частоты и улучшения качества синтезируемого напряжения инверторы, как правило, выполняют многоуровневыми [18-23]. При этом значительно усложняется схемотехника преобразователя частоты. К недостаткам такого преобразователя частоты можно отнести большие габариты, вес, а также низкую надежность при его использовании, поскольку выход любого из элементов силовой структуры приводит к выходу из строя всего электрического преобразователя. На современной элементной базе максимально достижимая мощность преобразователя частоты с трехуровневым инвертором составляет 5 МВт. При этом частота модуляции не превышает 400...500 Гц. Низкая частота модуляции влечет низкое качество модулированного напряжения на выходе инвертора.

Альтернативой преобразователю частоты с многоуровневыми инверторами являются каскадные преобразователи частоты [24-27]. Каскадный преобразователь частоты представляет собой матрицу, образованную из элементарных ячеек. Каждая ячейка представляет собой трехфазно-однофазный преобразователь частоты. При этом каждый однофазный преобразователь частоты выполнен на стандартных и широко распространенных низковольтных электронных ключах. Однако для питания каждого из однофазных преобразователей частоты требуются гальванически изолированные источники электрической энергии. Для гальванической развязки обычно используются многообмоточные трансформаторы. Выходные выводы ячеек каждой выходной фазы каскадного электрического преобразователя соединяются последовательно и образуют фазные выводы, при этом условные начала фаз каскадного электрического преобразователя соединяют между собой, а условные концы фаз подключают к нагрузке. Поскольку ячейки соединяются последовательно, то наращивание мощности каскадного электрического преобразователя происходит за счет увеличения его выходного напряжения, а не тока. Модулированное напряжение на выходе каскадного преобразователя является многоуровневым и имеет высокое качество [24-27]. 
Сравнительный анализ рассмотренных электрических преобразователей позволяет сделать вывод: в мощных гребных электроприводах предпочтительным является использование каскадного преобразователя.

Выбор структуры электродвижительного комплекса. При проектировании электроэнергетической системы судна обычно отдельно проектируются электростанция и электропривод движительного комплекса. Поэтому возникает необходимость использования согласующих трансформаторов, сложных распределительных устройств, наличие которых является наиболее существенным недостатком структуры гребного электропривода (см. рис. 1). Для исключения этого недостатка предлагается использовать комплексный подход, рассматривая электростанцию и электропривод движительного комплекса как единое целое. При этом из структуры можно исключить согласующий трансформатор напряжения, который является основным недостатком каскадного преобразователя частоты при его общепромышленном исполнении, а также значительно упростить главные и вторичные распределительные щиты.

Использование каскадного преобразователя частоты позволит реализовать движительный комплекс судна большой мощности без трансформатора при ограничениях, наложенных на параметры силовых электронных ключей. На рис. 4 представлена идея реализации гребного электропривода большой мощности без согласующего трансформатора с каскадным преобразователем частоты. В представленной структуре число гальванически изолированных друг от друга трехфазных обмоток электрического генератора равно числу трехфазнооднофазных ячеек каскадного преобразователя частоты.

Достоинством предложенной структуры является ее модульность, которая обеспечивает гибкость построения электродвижительной установки с различным числом генераторов, гребных электродвигателей и номинальным уровнем напряжения и тока. Управление зарядом конденсаторов в звене постоянного тока ячеек преобразователя может быть реализовано путем воздействия на обмотку возбуждения электрического генератора. Это позволит избавиться от устройств мягкого пуска. Кроме того, в долевых режимах работы движительного комплекса путем воздействия на систему возбуждения генератора можно повысить качество синтезируемого напряжения на выходе каскадного преобразователя частоты и, следовательно, ВШХ электропривода. 


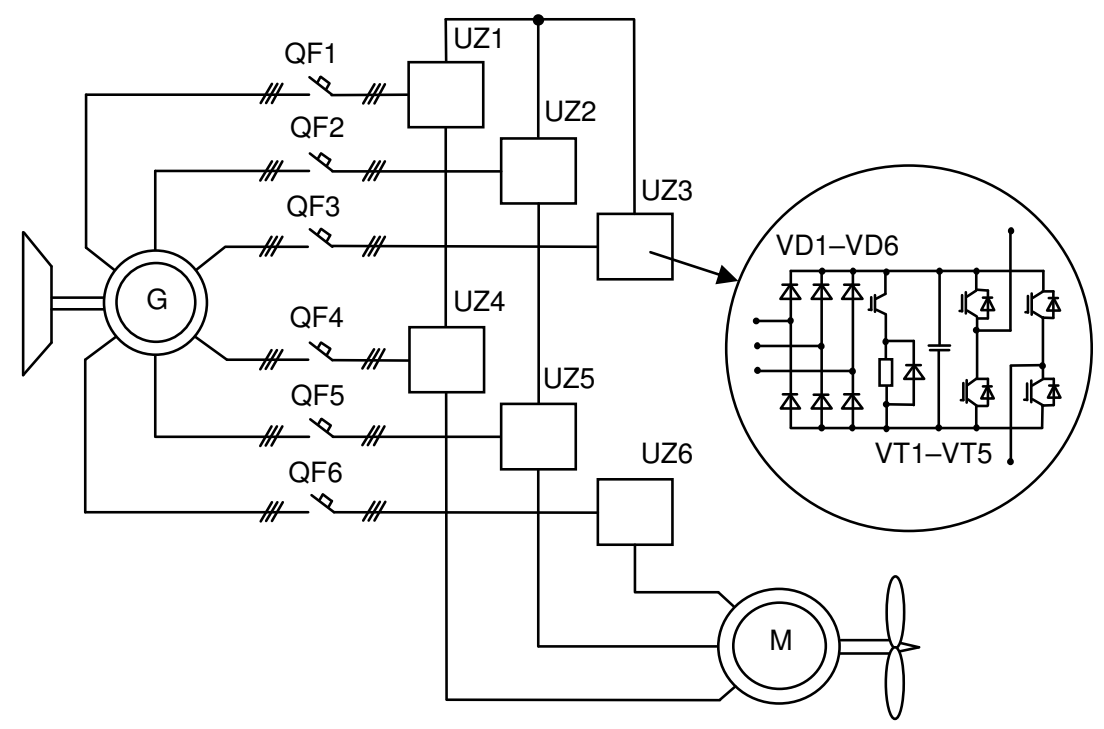

Рис. 4. Структура движительного комплекса судна большой мощности с каскадным электрическим преобразователем и одним многообмоточным электрическим генератором

Пример альтернативной реализации гребного электропривода ледокола проекта 22220 с каскадным преобразователем и РЭМАМПР приведен на рис. 5. Отличительной особенностью данной структуры является отсутствие согласующих трансформаторов и сложных и габаритных распределительных щитов. Для данной структуры произведен выбор компонентов и выполнен расчет энергетических и эксплуатационных характеристик. Расчет электрического преобразователя выполнен, исходя из допустимой перегрузки гребного электродвигателя по величине момента, кратной 1,8 номинала. В качестве силовых транзисторов выбраны модули фирмы «FUJI ELECTRIC» типа 1MBI3600VD-170E. При этом каждый из каскадных преобразователей частоты способен обеспечить регулирование действующего линейного напряжения на выходе в диапазоне от 0 до 7300 В. Результаты расчета массогабаритных показателей альтернативной структуры сравнивались с показателями исходной структуры гребного электропривода проекта 22220, содержащей трасформаторы, преобразователи частоты с многоуровневым инвертором напряжения и АД (рис. 6).

Исходя рис. 6, следует, что масса и габариты структуры на основе РЭМАМПР и каскадного преобразователя частоты значительно меньше. 


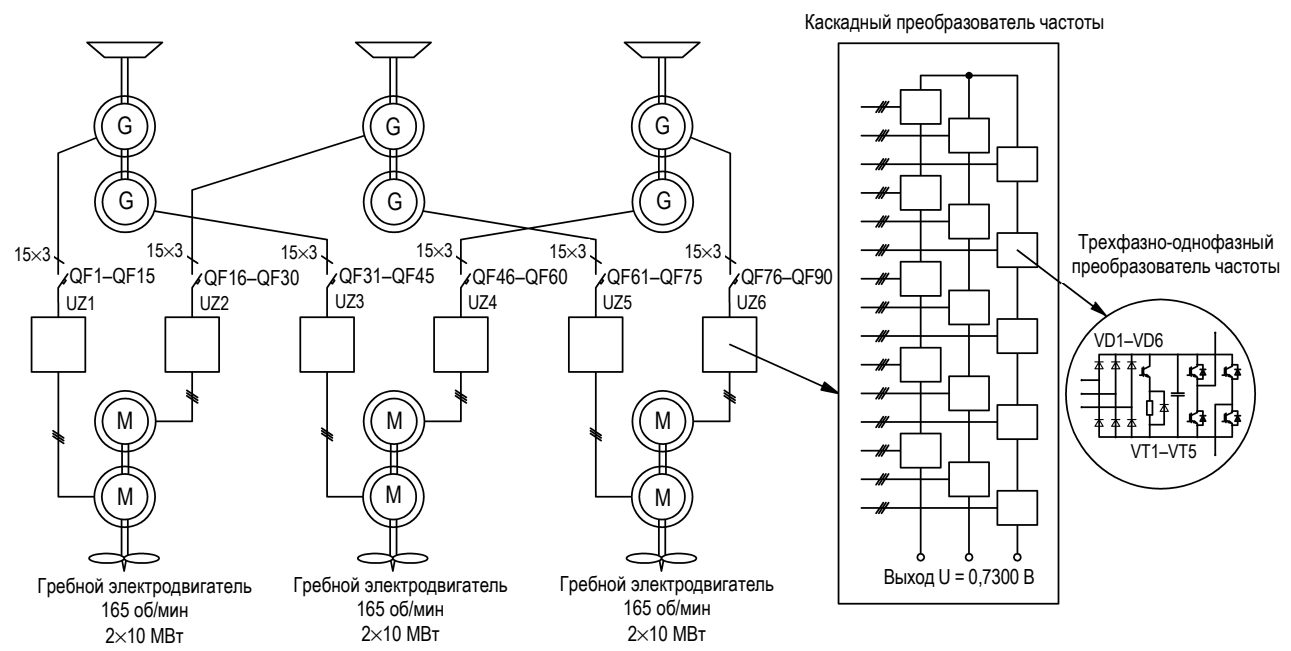

Рис. 5. Пример бестрансформаторной реализации гребного электропривода ледокола проекта 22220 с каскадным преобразователем и РЭМАМПР

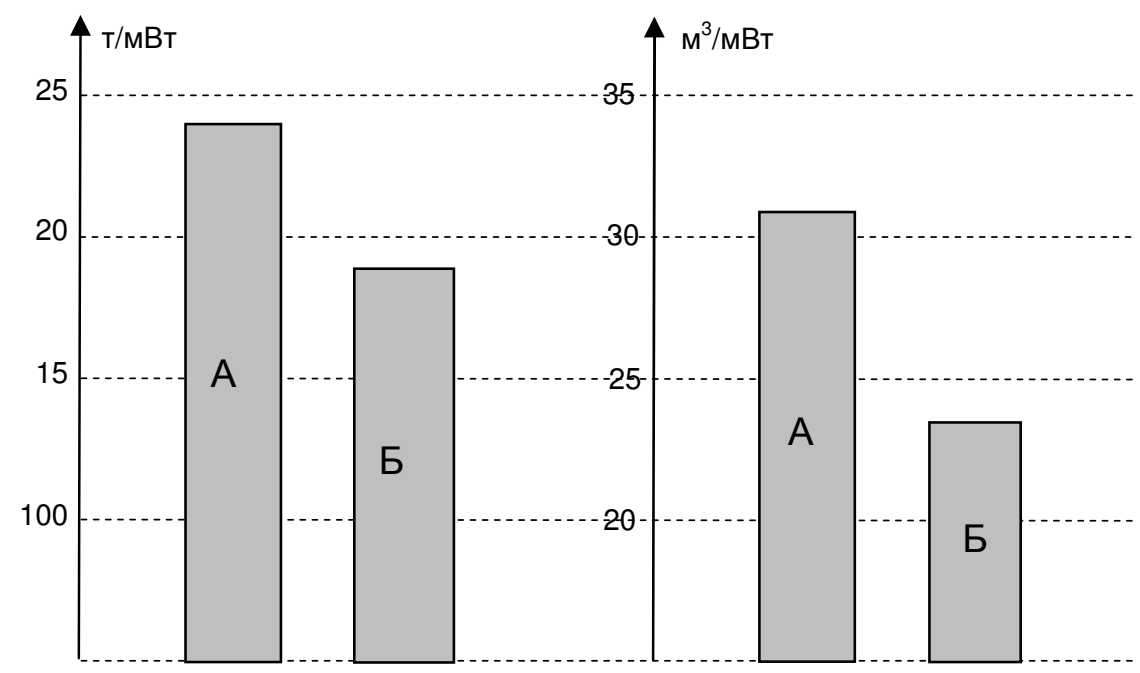

Рис. 6. Диаграмма удельной массы и удельного объема источников электроэнергии и электропривода проекта 22220 для варианта

А - исходного, Б - альтернативного

Кроме того, следует отметить, что отсутствуют согласующие трансформаторы, а главное распределительное устройство и различные распределительные щиты в предложенном варианте значительно проще. Качество синтезируемого напряжения в альтернативном варианте с каскадным преобразователем частоты будет значительно выше, чем у преобразователя с многоуровневым инвертором в исходном варианте. Следует отметить, 
структура альтернативного варианта имеет высокую надежность. Отказ одного из генераторов, ячейки преобразователя или гребного электродвигателя не приведет к отказу всей гребной электрической установки.

Выводы. Предложенная бестрасформаторная структура движительного комплекса судна обладает следующими достоинствами:

- отсутствие силового согласующего трансформатора, рассчитанного на полную мощность электропривода судна;

- использование простого серийно выпускаемого оборудования и элементной базы, высокая степень унификации, ремонтопригодности и взаимозаменяемости;

- использование низковольтных элементов и компонентов в трехфазно-однофазных ячейках преобразователя при возможности управлять мощным высоковольтным гребным электродвигателем;

- самое высокое качество синтезируемого напряжения и тока среди всех типов электрических преобразователей;

- возможность использования высокооборотного первичного теплового двигателя генераторного агрегата, который обладает лучшими массогабаритными и энергетическими характеристиками и увеличенным ресурсом;

- повышение коэффициента загрузки и ресурса первичных тепловых двигателей за счет возможности выбора числа работающих генераторных агрегатов при заданной мощности на валу гребного электродвигателя;

- модульность предложенной структуры обеспечивает унификацию и стандартизацию используемых элементов, а также простоту диагностики, ремонта и замены вышедшего из строя элемента;

- масштабируемость обеспечивается гибкостью построения системы с возможностью подключения дополнительных трехфазнооднофазных ячеек;

- снижение скорости нарастания напряжения $(d U / d t)$ на нагрузке, что помогает избежать резонансов электромагнитных процессов, происходящих в электроприводах гребных винтов;

- возможность реализовать гребной электропривод практически неограниченной мощности при ограничениях, наложенных на параметры используемых силовых ключей ячеек;

- высокая надежность, обусловленная простотой трехфазнооднофазных ячеек, а также возможностью исключения из работы отказавшей ячейки. 


\section{Библиографический список}

1. Структурные схемы гребных установок, анализ и перспективы развития / Н.А. Лазаревский, В.А. Хомяк, В.Ф. Самосейко, Ф.А. Гельвер // Судостроение. - 2012. - № 3.

2. Гребные электрические установки: учеб. пособие / А.Б. Дарьенков, Г.М. Мирясов, В.Г. Титов, М.Н. Охотников, Д.В. Умяров. Н. Новгород: Изд-во Нижегород. гос. техн. ун-та им. Р.Е. Алексеева, 2014. - 219 c.

3. Catalog Reference list offshore vessels. Low voltage propulsion, www.siemens.no/marine. - Norway, Sector Industry Marine and Shipbuilding. $-2013 .-$ P. 131.

4. Чепур Е. Россия строит маршрут для всего мира. На него не жалко триллиона // Lenta.Ru. - URL: https://news.mail.ru/politics/ 36076795/?frommail $=1$

5. Дьякова А.А., Дьяков О.Д. Северный морской путь: перспективы морских инноваций // Молодой ученый. - 2018. - № 44. - С. 235-239.

6. Создание систем электродвижения для судов различного назначения / В.И. Вершинин, С.В. Махонин, В.А. Паршиков, В.А. Хомяк // Труды Крылов. гос. науч. центра. - 2019. - Вып. 1(387). - С. 5-16.

7. Перспективы развития атомного ледокольного флота / М.М. Кашка, А.А. Смирнов, С.А. Головинский, В.М. Воробьев, А.В. Рыжков, Е.М. Бабич // Арктика: экология и экономика. - 2016. № 3(23). - С. 98-107.

8. Посадов Д.А., Титов В.Г., Умяров Д.В., Садиков Д.Г., Частотные электроприводы систем движения судов // Труды VIII Междунар. (XIX Bсерос.) конф. по автоматизир. электроприводу АЭП-2014; 7-9 октября 2014 г. - Саранск: Изд-во Мордов. ун-та, 2014. - С. 171-177.

9. Михайлов В.А., Рукавишников С.Б., Фрейдзон И.Р. Электродвижение судов и электропривод судовых механизмов. - Л.: Судостроение, 1965. - 608 с.

10. Реактивные электрические машины с зубчатым статором и ротором. Методика проектирования. Алгоритмы управления / В.Ф. Самосейко, Ф.А. Гельвер, В.А. Хомяк, Н.А. Лазаревский. - СПб.: Изд-во Крылов. гос. науч. центра, 2016. - 197 с.

11. Синхронные машины с анизотропной магнитной проводимостью ротора. Методика проектирования. Алгоритмы управления / В.Ф. Самосейко, Ф.А. Гельвер, В.А. Хомяк, Д.А. Хайров. - СПб.: Издво Крылов. гос. науч. центра, 2016. - 174 с. 
12. Самосейко В.Ф., Гельвер Ф.А., Белоусов И.В. Перспективы использования реактивных электрических машин в электроприводе // Труды IX Междунар. (X Всерос.) конф. по автоматизир. электроприводу АЭП-2016; Пермь, 3-7 октября 2016 г. (ICPDS 2016). - Пермь, 2016. - C. 359-363.

13. Гельвер Ф.А. Реактивная электрическая машина с анизотропной магнитной проводимостью ротора // Сб. докл. конф. молод. ученых и спец. - СПб.: Изд-во Крылов. гос. науч. центра, 2014.

14. Синхронная машина с анизотропной магнитной проводимостью ротора: патент № 2541513 / Ф.А. Гельвер, В.Ф. Самосейко, Н.А. Лазаревский, В.А. Хомяк, И.В. Гагаринов; заяв. № 2013118822 от 23.04.2013.

15. Synchronous reluctance motors (SynRM) [Электронный ресурс]. URL: http://new.abb.com/motors-generators/iec-low-voltage-motors/frequency-controlled-motors/synchronous-reluctance-motor-drive-packages (дата обращения: 10.04.2019).

16. IE4 SynRM motor-drive packages. Super premium efficiency for industry. BROCHURE. [Электронный ресурc]. - URL: https://searchext.abb.com/library/Download.aspx?DocumentID=3AUA0000132610\&Lan guageCode=en\&DocumentPartId=\&Action $=$ Launch $\quad$ (дата обращения: 10.04.2019).

17. Самосейко В.Ф., Гельвер Ф.А., Хомяк В.А. Сравнение различных типов реактивных электрических машин по энергетическим показателям // Труды Крылов. гос. науч. центра. - СПб., 2015. Вып. 89(373). - С. 201-208.

18. Бурдасов Б.К., Нестеров С.А., Федотов, Ю.Б. Многоуровневые и каскадные преобразователи частоты для высоковольтных электроприводов переменного тока // Apriori: электрон. науч. журнал. Сер. Естественные и технические науки. - 2015. - № 5.

19. Лазарев Г.Б. Высоковольтные преобразователи для частотнорегулируемого электропривода. Построение различных схем // Новости электротехники. - 2005. - № 2(32). - С. 30-36.

20. Пронин М.В., Воронцов А.Г. Силовые полностью управляемые полупроводниковые преобразователи (моделирование и расчет) / под ред. Е.А. Крутякова. - СПб.: Электросила, 2003. - 172 с.

21. Михеев К.Е., Томасов В.С. Анализ энергетических показателей многоуровневых полупроводниковых преобразователей систем 
электропривода // Научно-техн. вестник информац. технологий, механики и оптики. - 2012. - № 1(77). - С. 46-52.

22. Шрейнер Р.Т., Костылев А.В., Шилин С.И. Электропривод переменного тока с двухсекционным инвертором напряжения // Труды VII Междунар. (XVIII Всерос.) конф. по автоматизированному электроприводу АЭП-2012. - Иваново: Изд-во ИЭГУ, 2012. - С. 345-350.

23. Филатов В. Двух- и трехуровневые инверторы на IGBT. Перспективные решения // Силовая электроника. - 2012. - № 4. - С. 38-41.

24. Разработка преобразователя частоты каскадного типа для двигателя погружного насоса / И.В. Милюша, А.М. Мирзин, А.Д. Коротаев, С.В. Шутемов // Современные проблемы науки и образования. 2013. - № 6. -184 c.

25. Шавёлкин А.А. Каскадные многоуровневые преобразователи частоты с улучшенными энергетическими характеристиками // Технічна електродинаміка: наук.-приклад. журнал. Силова електроніка і енергоефективність. - Київ, 2010. - Ч. 1. - С. 65-70.

26. Шавёлкин А.А., Уланов Р.В. Возможности улучшения характеристик каскадных многоуровневых преобразователей частоты при использовании принципа асимметрии // Вісник Нац. техн. ун-ту "ХПІ". Харків, 2007. - № 25. - С. 122-132.

27. Многоуровневый преобразователь частоты с дифференцированными напряжениями уровней и байпасными полупроводниковыми ключами: пат. RU 2510769 / М.И. Хакимьянов, В.А. Шабанов; заяв. 2012148481/07 от 14.11.2012.

\section{References}

1. Lazarevskii N.A., Khomiak V.A., Samoseiko V.F., Gel'ver F.A. Strukturnye skhemy grebnykh ustanovok, analiz i perspektivy razvitiia [Structural diagrams of rowing facilities, analysis and development prospects]. Sudostroenie, 2012, no. 3.

2. Dar'enkov A.B., Miriasov G.M., Titov V.G., Okhotnikov M.N., Umiarov D.V. Grebnye elektricheskie ustanovki [Rowing electrical installations]. Nizhnii Novgorod: Nizhegorodskii gosudarstvennyi tekhnicheskii universitet imeni R.E. Alekseeva, 2014. 219 p.

3. Catalog Reference list offshore vessels. Low voltage propulsion, www.siemens.no/marine. Norway, Sector Industry Marine and Shipbuilding, 2013. $131 \mathrm{p}$. 
4. Chepur E. Rossiia stroit marshrut dlia vsego mira. Na nego ne zhalko trilliona [Russia is building a route for the whole world. It does not mind a trillion]. Lenta.Ru, available at: https://news.mail.ru/politics/ 36076795/?frommail=1

5. D'iakova A.A., D'iakov O.D. Severnyi morskoi put': perspektivy morskikh innovatsii [The Northern Sea Route: Prospects for Maritime Innovation]. Molodoi uchenyi, 2018, no. 44, pp. 235-239.

6. Vershinin V.I., Makhonin S.V., Parshikov V.A., Khomiak V.A. Sozdanie sistem elektrodvizheniia dlia sudov razlichnogo naznacheniia [Creation of electric propulsion systems for vessels of various purposes]. Trudy Krylovskogo gosudarstvennogo nauchnogo tsentra, 2019, iss. 1(387), pp. 5-16.

7. Kashka M.M., Smirnov A.A., Golovinskii S.A., Vorob'ev V.M., Ryzhkov A.V., Babich E.M. Perspektivy razvitiia atomnogo ledokol'nogo flota [Prospects for the development of atomic icebreaking fleet]. Arktika: ekologiia i ekonomika, 2016, no. 3(23), pp. 98-107.

8. Posadov D.A., Titov V.G., Umiarov D.V., Sadikov D.G. Chastotnye elektroprivody sistem dvizheniia sudov [Frequency electric drives of ship traffic systems]. Trudy VIII Mezhdunarodnoi (XIX Vserossiiskoi) konferentsii po avtomatizirovannomu elektroprivodu (AEP-2014), 7-9 October 2014. Saransk: Mordovskii universitet, 2014, pp. 171-177.

9. Mikhailov V.A., Rukavishnikov S.B., Freidzon I.R., Elektrodvizhenie sudov i elektroprivod sudovykh mekhanizmov [Ship electric power and ship gears]. Leningrad: Sudostroenie, 1965. 608 p.

10. Samoseiko V.F., Gel'ver F.A., Khomiak V.A., Lazarevskii N.A. Reaktivnye elektricheskie mashiny s zubchatym statorom i rotorom. Metodika proektirovaniia. Algoritmy upravleniia [Reactive electrical machines with serrated stator and rotor. Design methodology. Control algorithms]. Saint Petersburg: Krylovskii gosudarstvennyi nauchnyi tsentr, 2016. 197 p.

11. Samoseiko V.F., Gel'ver F.A., Khomiak V.A., Khairov D.A. Sinkhronnye mashiny s anizotropnoi magnitnoi provodimost'iu rotora. Metodika proektirovaniia. Algoritmy upravleniia [Synchronous machines with anisotropic magnetic conductivity of the rotor. Design methodology. Control algorithms]. Saint Petersburg: Krylovskii gosudarstvennyi nauchnyi tsentr, 2016. 174 p.

12. Samoseiko V.F., Gel'ver F.A., Belousov I.V. Perspektivy ispol'zovaniia reaktivnykh elektricheskikh mashin $\mathrm{v}$ elektroprivode [Prospects for the use of jet electric machines in the electric drive]. Trudy IX Mezhdunarodnoi (XX Vserossiiskoi) konferentsii po avtomatizirovannomu elektro- 
privodu AEP-2016. Perm: Permskii natsional'nyi issledovatel'skii politekhnicheskii universitet, 2016, pp. 359-363.

13. Gel'ver F.A. Reaktivnaia elektricheskaia mashina s anizotropnoi magnitnoi provodimost'iu rotora [Reactive electrical machine with anisotropic magnetic conductivity of the rotor]. Konferentsiia molodykh uchenykh $i$ spetsialistov. Sbornik dokladov. Saint Petersburg: Krylovskii gosudarstvennyi nauchnyi tsentr, 2014.

14. Gel'ver F.A., Samoseiko V.F., Lazarevskii N.A., Khomiak V.A., Gagarinov I.V. Sinkhronnaia mashina s anizotropnoi magnitnoi provodimost'iu rotora: patent № 2541513, zaiavka № 2013118822 ot 23.04.2013. [Synchronous machine with anisotropic magnetic conductivity of the rotor].

15. Synchronous reluctance motors (SynRM), available at: http://new.abb.com/motors-generators/iec-low-voltage-motors/frequencycontrolled-motors/synchronous-reluctance-motor-drive-packages (accessed 10 April 2019).

16. IE4 SynRM motor-drive packages. Super premium efficiency for industry. BROCHURE, available at: https://search-ext.abb.com/library/Download.aspx?DocumentID=3AUA0000132610\&LanguageCode=en \&DocumentP artId=\&Action=Launch (accessed 10 April 2019).

17. Samoseiko V.F., Gel'ver F.A., Khomiak V.A. Sravnenie razlichnykh tipov reaktivnykh elektricheskikh mashin po energeticheskim pokazateliam [Comparison of various types of reactive electrical machines for energy performance]. Trudy Krylovskogo gosudarstvennogo nauchnogo tsentra. Saint Petersburg, 2015, iss. 89(373), pp. 201-208.

18. Burdasov B.K., Nesterov S.A., Fedotov, Iu.B. Mnogourovnevye i kaskadnye preobrazovateli chastoty dlia vysokovol'tnykh elektroprivodov peremennogo toka [Multi-level and cascade frequency converters for high voltage ac drives]. Apriori: elektronnyi nauchnyi zhurnal. Estestvennye $i$ tekhnicheskie nauki, 2015, no. 5.

19. Lazarev G.B. Vysokovol'tnye preobrazovateli dlia chastotnoreguliruemogo elektroprivoda. Postroenie razlichnykh skhem [High-voltage converters for variable frequency drives.Construction of various schemes]. Novosti elektrotekhniki, 2005, no. 2(32), pp. 30-36.

20. Pronin M.V., Vorontsov A.G. Silovye polnost'iu upravliaemye poluprovodnikovye preobrazovateli (modelirovanie i raschet) [Power fully controlled semiconductor converters (simulation and calculation)]. Ed. E.A. Krutiakova. Saint Petersburg: Elektrosila, 2003. 172 p. 
21. Mikheev K.E., Tomasov V.S. Analiz energeticheskikh pokazatelei mnogourovnevykh poluprovodnikovykh preobrazovatelei sistem elektroprivoda [Analysis of the energy performance of multi-level semiconductor converters of electric drive systems]. Nauchno-tekhnicheskii vestnik informatsionnykh tekhnologii, mekhaniki i optiki, 2012, no. 1(77), pp. 46-52.

22. Shreiner R.T., Kostylev A.V., Shilin S.I. Elektroprivod peremennogo toka s dvukhsektsionnym invertorom napriazheniia [AC drive with twosection voltage inverter]. Trudy VII Mezhdunarodnoi (XVIII Vserossiiskoi) konferentsii po avtomatizirovannomu elektroprivodu AEP-2012. Ivanovo: Ivanovskii gosudarstvennyi energeticheskii universitet, 2012, pp. 345-350.

23. Filatov V. Dvukh- i trekhurovnevye invertory na IGBT. Perspektivnye resheniia [Two- and three-level IGBT inverters.Promising solutions]. Silovaia elektronika, 2012, no. 4, pp. 38-41.

24. Miliusha I.V., Mirzin A.M., Korotaev A.D., Shutemov S.V. Razrabotka preobrazovatelia chastoty kaskadnogo tipa dlia dvigatelia pogruzhnogo nasosa [Development of cascade type frequency converter for a submersible pump motor]. Sovremennye problemy nauki i obrazovaniia, 2013, no. 6, 184 p.

25. Shavelkin A.A. Kaskadnye mnogourovnevye preobrazovateli chastoty s uluchshennymi energeticheskimi kharakteristikami [Cascade multi-level frequency converters with improved energy performance]. Tekhnichna elektrodinamika. Naukovo-prikladnii zhurnal. Silova elektronika i energoefektivnist'. Kiïv, 2010, part 1, pp. 65-70.

26. Shavelkin A.A., Ulanov R.V. Vozmozhnosti uluchsheniia kharakteristik kaskadnykh mnogourovnevykh preobrazovatelei chastoty pri ispol'zovanii printsipa asimmetrii [Possibilities for improving the performance of multi-level cascade frequency converters using asymmetry principle]. Visnik Natsional'nogo tekhnichnogo universitetu "KhPI". Kharkiv, 2007, no. 25, pp. 122-132.

27. Khakim'ianov M.I., Shabanov V.A., Mnogourovnevyi preobrazovatel' chastoty $\mathrm{s}$ differentsirovannymi napriazheniiami urovnei $\mathrm{i}$ baipasnymi poluprovodnikovymi kliuchami [Multilevel frequency converter with differentiated level voltages and bypass semiconductor switches]. Patent Rossiiskaia Federatsiia no. 2510769 (2012).

\section{Сведения об авторах}

Гельвер Фёдор Андреевич (Санкт-Петербург, Россия) - кандидат технических наук, доцент, начальник лаборатории филиала «ЦНИИ СЭТ» Крыловского государственного научного центра (196128, Санкт- 
Петербург, ул. Благодатная, 6), доцент кафедры «Электропривод и электрооборудование береговых установок» Государственного университета морского и речного флота им. адмирала С.О. Макарова (198035, СанктПетербург, ул. Двинская, 5/7, e-mail: gelver@bk.ru).

Белоусов Игорь Владимирович (Санкт-Петербург, Россия) - доцент кафедры «Электропривод и электрооборудование береговых установок» Государственного университета морского и речного флота им. адмирала С.О. Макарова (198035, Санкт-Петербург, ул. Двинская, 5/7), ведущий инженер филиала «ЦНИИ СЭТ» Крыловского государственного научного центра (196128, Санкт-Петербург, ул. Благодатная, 6, e-mail:ibel@bk.ru).

Самосейко Вениамин Францевич (Санкт-Петербург, Россия) доктор технических наук, профессор кафедры «Электропривод и электрооборудование береговых установок» Государственного университета морского и речного флота им. адмирала С.О. Макарова (198035, Санкт-Петербург, ул. Двинская, 5/7), e-mail: samoseyko@mail.ru).

\section{About the authors}

Gelver Fedor Andreevich (Saint Petersburg, Russian Federation) is a Ph.D. in Technical Sciences, Associate Professor, Head of the laboratory of the branch "TsNII SET" Krylov State Research Center (196128, Saint Petersburg, 6, Blagodatnaya str.), Associate Professor "Electric drive and electrical equipment of shore installations" GUMRF named after Admiral S.O. Makarov (198035, Saint Petersburg, 5/7, Dvinskaya str., e-mail: gelver@bk.ru).

Belousov Igor Vladimirovich (Saint Petersburg, Russian Federation) is a Associate Professor of the Department "Electric Drive and Electrical Equipment of Coastal Installations" FSBEI HE "GUMRF named after Admiral S.O. Makarov (196128, Saint Petersburg, 1980, 5/7, Dvinskaya str.), leading engineer of the branch «TsNII SET» FGUP «Krylovskiy gosudarstvennyy nauchnyy tsentr» (196128, Saint Petersburg, 6, Blagodatnaya str., e-mail: ibel@bk.ru).

Samoseiko Veniamin Frantsevich (Saint Petersburg, Russian Federation) is a Doctor of Technical Sciences, Professor Department of the electric drive and electrical equipment onshore installations Admiral S.O. Makarov State University of Maritime and Inland Shipping (198035, Saint Petersburg, 5/7, Dvinskaya str., e-mail: samoseyko@mail.ru).

Получено 15.04.2019 